\title{
Chiral Differentiation of Amino Acids by In-Source Collision-Induced Dissociation Mass Spectrometry
}

\author{
Xianglei Kong, ${ }^{*}$ Zhaiyi Huo, and Wei Zhai \\ State Key Laboratory and Institute of Elemento-Organic Chemistry, Nankai University, Collaborative Innovation Center of \\ Chemical Science and Engineering, Tianjin 300071, China
}

\begin{abstract}
Chiral recognition of D- and L-amino acids is achieved by a method combining electrospray ionization (ESI) and in-source collision-induced dissociation (CID) mass spectrometry (MS). Trimeric cluster ions $\left[\mathrm{Cu}^{\mathrm{II}}(\mathrm{A})(\mathrm{ref})_{2}-\mathrm{H}\right]^{+}$are formed by ESI of mixtures of D- or L-analyte amino acid (A), chiral reference (ref) and $\mathrm{CuSO}_{4}$. By increasing the applied voltage in the ESI source region, the trimeric ions become unstable and dissociate progressively. Thus chiral differentiation of the analyte can be achieved by comparing the dependence of their relative intensities to a reference ion on applied voltages. The method does not need MS/MS technique, thus can be readily performed on single-stage MS instruments by turning the voltage of sampling cone.
\end{abstract}

Please cite this article as: X. Kong, et al., Chiral Differentiation of Amino Acids by In-Source CollisionInduced Dissociation Mass Spectrometry, Mass Spectrom (Tokyo) 2014; 3(2): S0031; DOI: 10.5702/ massspectrometry.S0031

Keywords: chiral differentiation, amino acids, in-source CID, electrospray ionization, cone voltage

(Received September 12, 2013; Accepted January 21, 2014)

\section{INTRODUCTION}

Mass spectrometry (MS) was first thought as a blind technique for chiral differentiation many years ago, but now it is accepted as a powerful analytical tool for chiral analysis in the gas phase. ${ }^{1)}$ This can be greatly attributed to the development of kinds of soft ionization methods, especially the one of electrospray ionization (ESI). ${ }^{2)}$ ESI makes the formation of noncovalent complex ions in the gas phase performable, which provides a chiral surrounding for enantiomers. Usually, three kinds of MS-based methods have been applied for chiral discrimination. The first one is to measure the relative abundance of diastereomeric complex ions formed by the analyte and a particular reference molecule. ${ }^{3-5)}$ The second one is to investigate the exchange rate in the reaction of the diastereomeric host-guest complexes with a neutral reagent (guest). ${ }^{6-10)}$ The third one is to compare the difference in fragmentation pattern caused by collisioninduced dissociation (CID) of the diastereomeric adduct ions. $^{11-20)}$

Among these different chiral analysis methods, the kinetic method has been proven to be the most widely applied one. ${ }^{1,12-20)}$ In this method, cluster ions $\left[\mathrm{M}^{\mathrm{II}}(\mathrm{A})(\mathrm{ref})_{2}-\mathrm{H}\right]^{+}$consisting of a transition metal ions $\left(\mathrm{M}^{\mathrm{II}}\right)$, an analyte molecule (A) and two molecules of chiral reference (ref), are generated by ESI source and isolated for CID study. By measuring the abundance ratios of two fragment ions of $\left[\mathrm{M}^{\mathrm{II}}(\mathrm{A})(\mathrm{ref})\right.$ $\mathrm{H}]^{+}$and $\left[\mathrm{M}^{\mathrm{II}}(\mathrm{ref})_{2}-\mathrm{H}\right]^{+}$generated by CID of the isolated diastereomeric ions, chiral recognition can be achieved.
The method has been successful used for many kinds of chiral molecules, including amino acids, sugars, and chiral drugs. ${ }^{12-20)}$

In the kinetic method, the isolation of the precursor ions before CID is very important, since it not only makes the method applicable to analytes in complex matrixes, but also improves the repeatability of the experimental results and makes enantiometric measurement performable. However, it also brings some limitations. Tandem MS is needed in these experiments and a clear isolation of the precursor ions is also very important. In some cases, the signals of diastereomeric ions are too weak to be isolated effectively. In other cases, some ions with very close $m / z$ can be generated in the ESI processes, and this also makes a clear selection of the precursor ions very difficult.

Can we perform the chiral identification based on nontandem MS methods? In fact, the first class method discussed above is based on non-tandem MS. Generally, in these methods, isotopically labeled compounds were used. ${ }^{3)}$ Chiral identification can be achieved by comparing abundances of the labeled and unlabeled complex ions. However, the need of isotopically labeled compounds also limits its application very much. Here we try a different way to fulfill this goal. It is well known that the ions generated by ESI method can be accelerated by increasing the applied voltages. The acceleration prompts collisions of the initially generated ions with surrounding gas molecules, causing the dissociation of them. The technique is usually called as in-source CID. ${ }^{21-23)}$ It is also referred with different names, such as: nozzle-skimmer fragmentation, ${ }^{24)}$ skimmer-CID or

* Correspondence to: Xianglei Kong, State Key Laboratory and Institute of Elemento-Organic Chemistry, Nankai University, Collaborative Innovation Center of Chemical Science and Engineering, Tianjin 300071, China, e-mail: kongxianglei@nankai.edu.cn 



Fig. 1. ESI mass spectra of mixtures of $\mathrm{CuSO}_{4}$ and L-Trp with enantiomers of Met under different cone voltages: (a) L-Met, $20 \mathrm{~V}$; (b) D-Met, $20 \mathrm{~V}$; (c) L-Met, 25 V; (d) D-Met, 25 V; (e) L-Met, 40 V; (f) D-Met, $40 \mathrm{~V}$.

source-CID. ${ }^{25)}$ It is not a real MS/MS method since the precursor ions cannot be selected and isolated, and the experiments can be performed in single-stage MS instruments. Here the method of in-source CID was directly applied in the chiral analysis of amino acids, and the results indicate its performability and advantages.

\section{EXPERIMENTAL}

All experiments were performed with a 7.0 Tesla Fourier transform ion cyclotron resonance (FT ICR) mass spectrometer (IonSpec) in the positive ion mode. Complex ions were generated by electrospraying $50 \%$ methanol solutions containing $0.5 \mathrm{mM}$ analyte, $1 \mathrm{mM}$ L-tryptophan (L-Trp) or L-proline (L-Pro) and $0.25 \mathrm{mM} \mathrm{CuSO}_{4}$ through an infusion rate of $4 \mu \mathrm{L} / \mathrm{min}$. ZSpray ESI source was used with the probe biased at $3.6 \mathrm{kV}$. Room-temperature $\mathrm{N}_{2}$ was used as cone gas. Samples of amino acids and $\mathrm{CuSO}_{4}$ were brought from Sigma and Tianjin Guangfu Fine Chemical Research Institute, respectively.

\section{RESULTS AND DISCUSSION}

\section{Chiral differentiation of $\mathbf{L} / \mathrm{D}$-methionine}

Based on the kinetic method, Cooks et al. have found that L-Trp could be selected as a very good reference molecule for the chiral differentiation of $\mathrm{L} / \mathrm{D}$-methionine (Met). With the help of the divalent transition-metal ion of $\mathrm{Cu}^{2+}$, the value of chiral selectively $R_{\text {chiral }}$ for Met could be as high as 7.6. ${ }^{1)}$ Here we choose the same system to test our method. The complex ions were generated by ESI of the mixed solution. With a cone voltage at $20 \mathrm{~V}$ (typical voltages for normal ESI experiments on the same instrument are between $20-25 \mathrm{~V}$ ), signals of trimeric cluster ions of $\left[\mathrm{Cu}(\mathrm{Met})(\mathrm{L}-\mathrm{Trp})_{2}-\mathrm{H}\right]^{+}(\mathrm{m} / z$ 619.15) were detected for both L-Met and D-Met. And the relative abundance of the former was found to be higher than that of the latter. In order to make sure this chiral difference, a reference complex ion of $\left[\mathrm{Cu}(\mathrm{L}-\mathrm{Trp})_{3}-\mathrm{H}\right]^{+}(\mathrm{m} / z$ 674.19) in the same mass spectrum was selected. The relative intensity of the trimeric cluster ion in each mass spectrum was calculated as $I^{\mathrm{r}}=I_{619} / I_{674}$. The ratio of $I_{\mathrm{L}-\text { Met }}^{\mathrm{r}}$ to $I_{\mathrm{D}-\text { Met }}^{\mathrm{r}}$, defined as $R_{\mathrm{chi}}=I_{\mathrm{L}-\mathrm{Met}}^{\mathrm{r}} / I_{\mathrm{D}-\mathrm{Met}}^{\mathrm{r}}$, indicated the level of chiral discrimination achievable. As shown in Figs. 1(a) and (b), the value of $R_{\text {chi }}$ under this particular conditions is 2.6. An increase of cone voltage to $25 \mathrm{~V}$ did not change the intensity of $\left[\mathrm{Cu}(\mathrm{L}-\mathrm{Trp})_{3}\right.$ $\mathrm{H}]^{+}$much, but decreased intensities of $\left[\mathrm{Cu}(\mathrm{Met})(\mathrm{L}-\mathrm{Trp})_{2}-\mathrm{H}\right]^{+}$ greatly. The corresponding value of $R_{\text {chi }}$ increased to 12.2 . But none ions of $\left[\mathrm{Cu}(\mathrm{Met})(\mathrm{L}-\mathrm{Trp})_{2}-\mathrm{H}\right]^{+}$for L-Met and D-Met could survive under a higher cone voltage of $40 \mathrm{~V}$ (Fig. 1).

Although both intensities of them decreased with the increase of cone voltage, the chiral discrimination can be reflected by comparing their responses to the change of cone voltage. Figure 2 shows the relationships of relative intensities of $\left[\mathrm{Cu}(\mathrm{Met})(\mathrm{L}-\mathrm{Trp})_{2}-\mathrm{H}\right]^{+}$to reference ion $[\mathrm{Cu}(\mathrm{L}-$ $\left.\operatorname{Trp})_{3}-\mathrm{H}\right]^{+}$to the values of cone voltage. It is reflected that the ion of $\left[\mathrm{Cu}(\mathrm{D}-\mathrm{Met})(\mathrm{L}-\mathrm{Trp})_{2}-\mathrm{H}\right]^{+}$is less stable than $[\mathrm{Cu}(\mathrm{L}-\mathrm{Met})$ $\left.(\mathrm{L}-\mathrm{Trp})_{2}-\mathrm{H}\right]^{+}$. Under a cone voltage between 21 to $25 \mathrm{~V}$, both ions decreased quickly with the increase of voltage. When the voltage changes from $25 \mathrm{~V}$ to $29 \mathrm{~V}$, signals of [Cu(L-Met) $\left.(\mathrm{L}-\mathrm{Trp})_{2}-\mathrm{H}\right]^{+}$are weak but relatively stable, while those of 


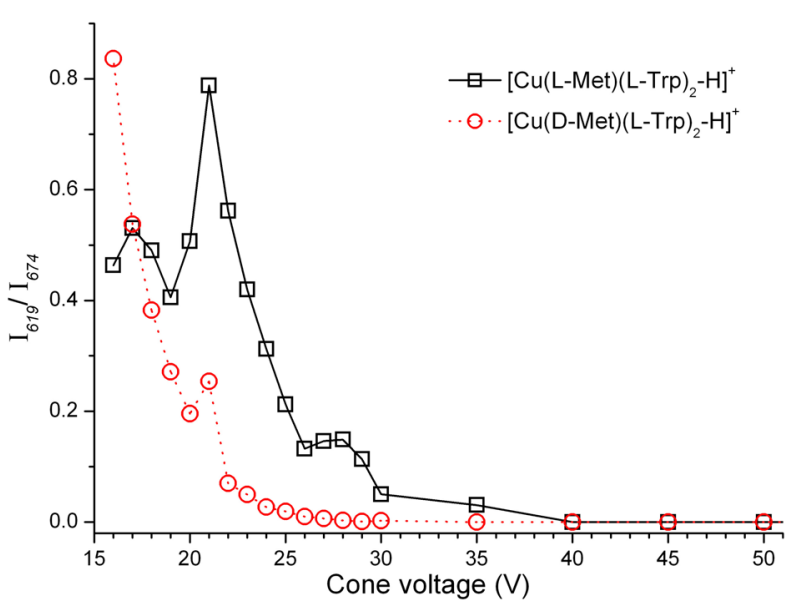

Fig. 2. Plots of relative intensities of $\left[\mathrm{Cu}(\mathrm{Met})(\mathrm{L}-\mathrm{Trp})_{2}-\mathrm{H}\right]^{+}$to $[\mathrm{Cu}(\mathrm{L}-$ $\left.\operatorname{Trp})_{3}-\mathrm{H}\right]^{+}\left(I_{619} / I_{674}\right)$ versus cone voltages.

$\left[\mathrm{Cu}(\mathrm{L}-\mathrm{Met})(\mathrm{L}-\mathrm{Trp})_{2}-\mathrm{H}\right]^{+}$are so weak and can be hardly detected. A higher voltage of $30 \mathrm{~V}$ or more makes the detection in both cases unpractical. Since the chiral differentiation based on Fig. 2 does not depend on the intensity of a single ion peak under a particular condition, the reliability and repeatability of the experimental results for qualitative chiral analysis are greatly improved.

\section{Chiral differentiation of $\mathrm{L} / \mathrm{D}$-Phe}

The second example selected here is L/D-phenylalanine (Phe). Based on the kinetic methods, Cooks et al. have found that L-Pro could be used as an effective reference ion $\left(R_{\text {chiral }}=7.4\right) .{ }^{14)}$ As Fig. 3(a) shows, the mass spectrum of the mixture of L-Phe and L-Pro under a general ESI condition (with cone voltage of $25 \mathrm{~V}$ ) shows that a number of complex ions could be formed. Most of these complex ions include one unit of $\mathrm{Cu}^{2+}$, and the trimeric cluster ions of $[\mathrm{Cu}(\mathrm{L}-$ Phe)(L-Pro) $\left.{ }_{2}-\mathrm{H}\right]^{+}(m / z$ 457.13) can be detected readily. Only several complex ions with two copper atoms were detected. Under a high cone voltage at $60 \mathrm{~V}$, the corresponding mass spectrum changes a lot. None of these previous complex ions including one copper atom existed, and signals of complex ions with two copper atoms are enhanced greatly (Fig. 3(b)).

Chiral differentiation of L-Phe and D-Phe was also performed by comparing the intensity variation caused by the increase of cone voltage from $25 \mathrm{~V}$ to $65 \mathrm{~V}$. Figure 4 shows the results. It has been found the complex ion of $\left[\mathrm{Cu}_{2}\left(\mathrm{~L}^{-}\right.\right.$ Pro $\left.)_{4}-3 \mathrm{H}\right]^{+}(m / z 583.09)$ could be observed in all mass spectra. Thus the ion was selected as the reference ion here. Like those observed in Fig. 2, the ion of $\left[\mathrm{Cu}(\mathrm{D}-\mathrm{Phe})(\mathrm{L}-\mathrm{Pro})_{2}-\mathrm{H}\right]^{+}$ is found to be less stable, and decreases its peak intensities quickly. Under a voltage of $35 \mathrm{~V}$, the relative intensity of $\left[\mathrm{Cu}(\mathrm{D}-\mathrm{Phe})(\mathrm{L}-\mathrm{PrO})_{2}-\mathrm{H}\right]^{+}$decreases to less than 0.05 , and the corresponding value of $R_{\text {chi }}$ increases to 35 .

It should be noticed that the effects of chiral differentiation also depend on the selected reference ions in the mass spectra. A good selection of the reference ion not only improves the performability and reproducibility of results, but also highlights the difference. For example, a different reference ion was selected and applied in the analysis of the example of $\mathrm{L} / \mathrm{D}-\mathrm{Phe}$. A careful inspection of the trimeric cluster ions of $\left[\mathrm{Cu}(\mathrm{Phe})(\mathrm{L}-\mathrm{Pro})_{2}-\mathrm{H}\right]^{+}$under different volt-
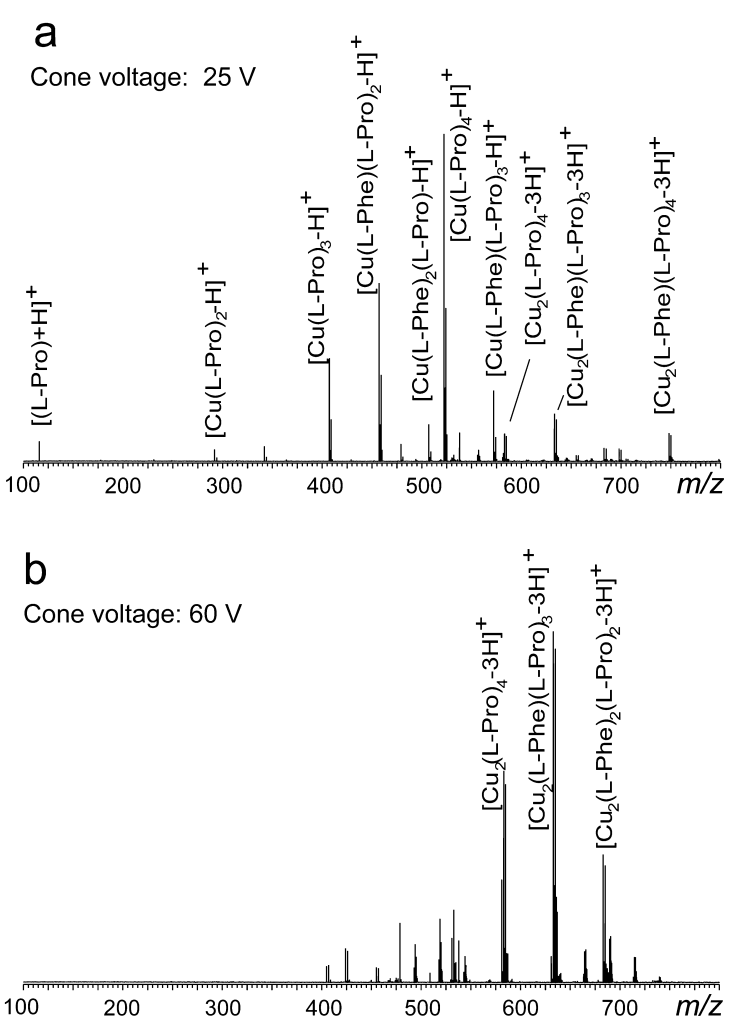

Fig. 3. ESI mass spectra of mixtures of $\mathrm{CuSO}_{4}$ and L-Pro with L-Phe under different cone voltages at (a) $25 \mathrm{~V}$, (b) $60 \mathrm{~V}$.

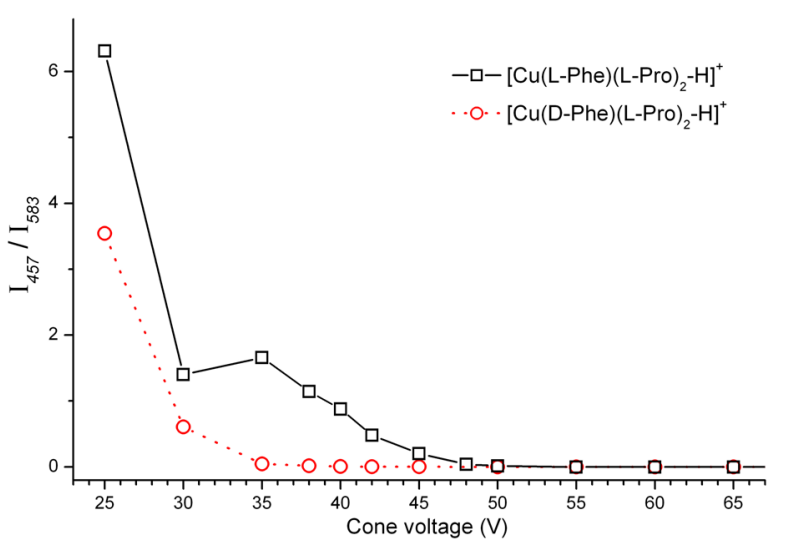

Fig. 4. Plots of relative intensities of $\left[\mathrm{Cu}(\mathrm{Phe})(\mathrm{L}-\mathrm{Pro})_{2}-\mathrm{H}\right]^{+}$to $\left[\mathrm{Cu}_{2}(\mathrm{~L}-\right.$ Pro $\left.)_{4}-3 \mathrm{H}\right]^{+}\left(I_{457} / I_{583}\right)$ versus cone voltages.

ages show some details. That is, as the increase of the cone voltage, complex ions of $\left[\mathrm{Cu}(\mathrm{Phe})(\mathrm{L}-\mathrm{Pro})_{2}-\mathrm{H}\right]^{+}$were progressively replaced by a different ion with a very close $\mathrm{m} / \mathrm{z}$ (at 455.02) for both $\mathrm{L}_{-}$and D-Phe (Fig. 5). With the accurate $\mathrm{m} / \mathrm{z}$ measurement obtained with the FT ICR MS and their isotropic distributions, these ions were identified as $\left[\mathrm{Cu}_{2}(\mathrm{Phe})\right.$ (L-Pro) $\left.)_{2}-\mathrm{C}_{5} \mathrm{H}_{6}\right]^{+}$. By comparing the intensities of the two ions under different voltages, the chiral differentiation can be fulfilled, too. As shown in Fig. 6, the responses of the two ions on the cone voltage for both $\mathrm{L}$ - and $\mathrm{D}$-Phe are similar. The increase of voltage causes the signals of ions at $\mathrm{m} / \mathrm{z} 457$ and 455 to decrease and increase, respectively. But their corresponding cross points of the two curves are different. For $\mathrm{L}^{-}$and $\mathrm{D}$-Phe, the cross point is $48 \mathrm{~V}$ and $37 \mathrm{~V}$, respectively. Based on these results, the direct chiral differentiation of the enantiomers can also be achieved readily by compar- 

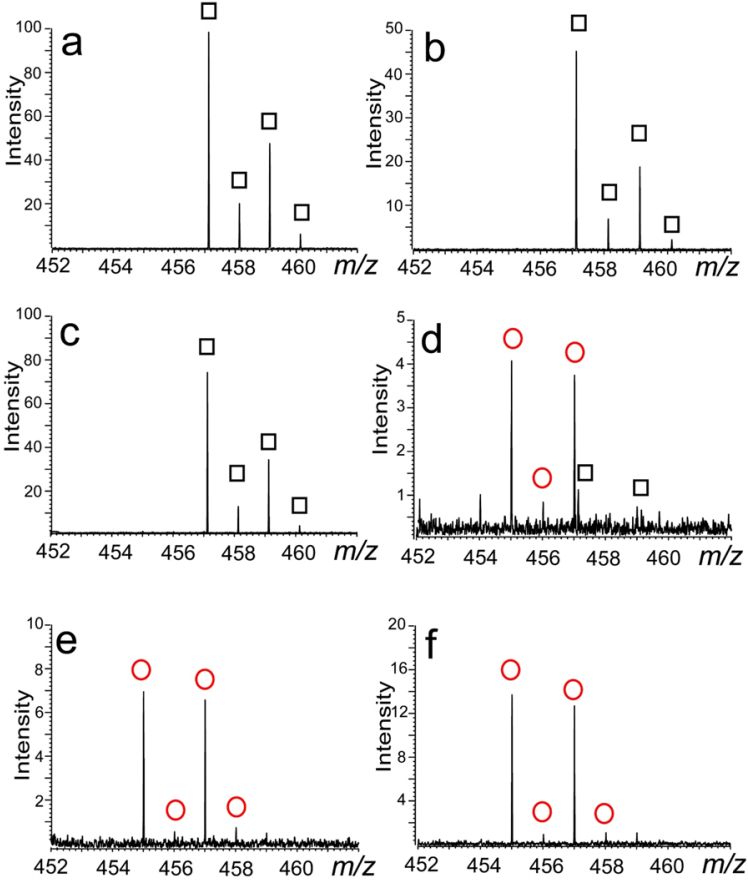

Fig. 5. ESI mass spectra (in the range of $m / z 452-462$ ) of mixtures of $\mathrm{CuSO}_{4}$ and L-Pro with enantiomers of Phe under different cone voltages: (a) L-Phe, $25 \mathrm{~V}$; (b) D-Phe, $25 \mathrm{~V}$; (c) L-Phe, $40 \mathrm{~V}$; (d) D-Phe, $40 \mathrm{~V}$; (e) L-Phe, $60 \mathrm{~V}$; (f) D-Phe, 60 V. The squares indicate the isotropic peaks of $\left[\mathrm{Cu}(\mathrm{Phe})(\mathrm{L}-\mathrm{Pro})_{2}-\mathrm{H}\right]^{+}$, and the circles indicate those of $\left[\mathrm{Cu}_{2}(\mathrm{Phe})(\mathrm{L}-\mathrm{Pro})_{2}-\mathrm{C}_{5} \mathrm{H}_{6}\right]^{+}$.
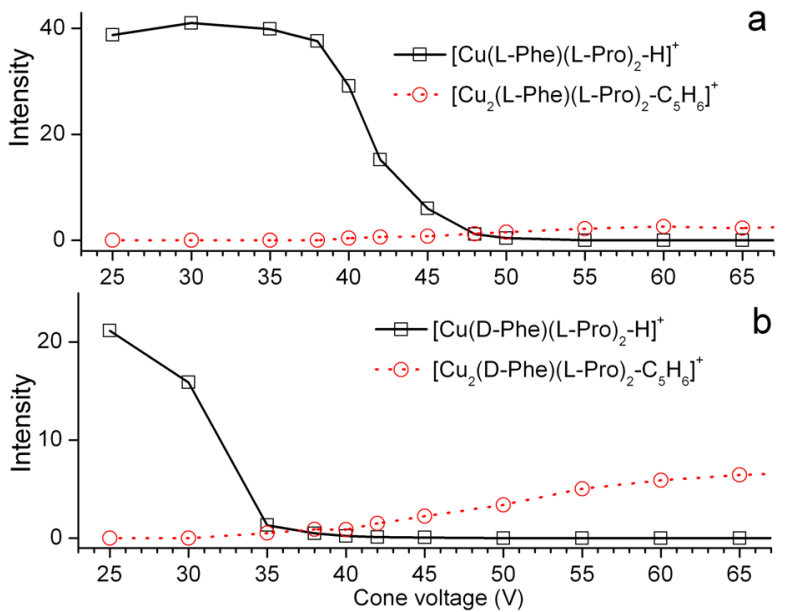

Fig. 6. Plots of intensities of $\left[\mathrm{Cu}(\mathrm{Phe})(\mathrm{L}-\mathrm{Pro})_{2}-\mathrm{H}\right]^{+}$(squares in solid line) and $\left[\mathrm{Cu}_{2} \text { (Phe)(L-Pro) }{ }_{2}-\mathrm{C}_{5} \mathrm{H}_{6}\right]^{+}$(circles in dot line) versus cone voltages for (a) L-Phe and (b) D-Phe.

ing their mass spectra in a small $\mathrm{m} / \mathrm{z}$ region under a selected cone voltage (for example, a voltage at $40 \mathrm{~V}$ is a good choice for this case, as shown in Figs. 6(b) and (c)).

\section{CONCLUSION}

In summary, the method of in-source CID was applied here to recognize the chirality of amino acids. Previous results obtained based on the kinetic method, including the choose of reference chiral molecules and the metal ions for a particular analyte, can be directly used in this experiment. A reference ion observed in the mass spectrum should be selected firstly. Due to different stabilities of diastereomeric trimeric cluster ions $\left[\mathrm{M}^{\mathrm{II}}(\mathrm{A})(\mathrm{ref})_{2}-\mathrm{H}\right]^{+}$, chiral discrimination of the analyte can be achieved by comparing their dependences of their relative intensities to the reference ion on cone voltages applied. The selection of the reference peak is important to the effect of chiral differentiation. The experiments do not need MS/MS technique, thus can be readily performed on single-stage MS instruments equipped with ESI source. Some further experiments, such as its performability for other chiral samples, or samples in complicated surroundings and possible semiquantitative or quantitative chiral analysis, need to be studied further.

\section{Acknowledgements}

Financial support from the National Natural Science Foundation of China (Nos. 21172121, 21121002) and the Fundamental Research Funds for the Central Universities are gratefully acknowledged.

\section{REFERENCES}

1) W. A. Tao, R. G. Cooks. Chiral analysis by MS. Anal. Chem. 74: 25A-31A, 2003

2) J. B. Fenn, M. Mann, C. K. Meng, S. F. Wong, C. M. Whitehouse. Electrospray ionization for mass spectrometry of large biomolecules. Science 246: 64-71, 1989.

3) M. Sawada. Chiral recognition detected by fast atom bombardment mass spectrometry. Mass Spectrom. Rev. 16: 73-90, 1997.

4) P. Krishna, S. Prabhakar, M. Manoharan, E. D. Jemmis, M. Vairaman. Chiral recognition and the determination of optical purity of some amino acids ester salts using monosaccharides as chiral selectors under liquid secondary ion mass spectral conditions. Chem. Commun. (Camb.), 1215-1216, 1999.

5) M. Speranza. Enantioselectivity in gas-phase ion-molecule reactions. Int. J. Mass Spectrom. 232: 277-317, 2004.

6) J. Ramirez, F. He, C. B. Lebrilla. Gas-phase chiral differentiation of amino acid guests in cyclodextrin hosts. J. Am. Chem. Soc. 120: 7387-7388, 1998.

7) D. V. Dearden, C. Dejsupa, Y. J. Liang, J. S. Bradshaw, R. M. Izatt. Intrinsic contributions to chiral recognition: Discrimination between enantiomeric amines by dimethyldiketopyridino18-crown-6 in the gas phase. J. Am. Chem. Soc. 119: 353-359, 1997.

8) J. Ramirez, S. Ahn, G. Grigorean, C. B. Lebrilla. Evidence for the formation of gas-phase inclusion complexes with cyclodextrins and amino acids. J. Am. Chem. Soc. 122: 6884-6890, 2000.

9) A. Filippi, F. Gasparrini, M. Pierini, M. Speranza, C. Villani. Exceptional gas-phase enantioselectivity of chiral tetramide macrocycles. J. Am. Chem. Soc. 127: 11912-11913, 2005.

10) X. Cong, G. Czerwieniec, E. McJimpsey, S. Ahn, F. A. Troy, C. B. Lebrilla. Structural relationships in small molecule interactions governing gas-phase enantioselectivity and zwitterionic formation. J. Am. Soc. Mass Spectrom. 17: 442-452, 2006.

11) Z.-P. Yao, T. S. M. Wan, K.-P. Kwong, C. T. Che. Chiral analysis by electrospray ionization mass spectrometry/mass spectrometry. Chiral recognition of 19 common amino acids. Anal. Chem. 72: 5383-5393, 2000

12) H.-J. Lu, Y.-L. Guo. Evaluation of chiral recognition characteristics of metal and proton complexes of di- $o$-benzoyl-tartaric acid dibutyl ester and L-tryptophan in the gas phase. J. Am. Soc. Mass Spectrom. 14: 571-580, 2003.

13) W. A. Tao, D. Zhang, F. Wang, P. D. Thomas, R. G. Cooks. Kinetic resolution of $\mathrm{D}, \mathrm{L}$-amino acids based on gas-phase dissociation of copper(II) complexes. Anal. Chem. 71: 4427-4429, 1999.

14) W. A. Tao, D. Zhang, E. N. Nokolaev, R. G. Cooks. Copper(II)- 
assisted enantiometric analysis of D, L-amino acids using the kinetic method: Chiral recognition and quantification in the gas phase. J. Am. Chem. Soc. 122: 10598-10609, 2000.

15) D. V. Augusti, R. Augusti, R. Carazza, R. G. Cooks. Quantitative determination of the enantiomeric composition of thalidomide solutions by electrospray ionization tandem mass spectrometry. Chem. Commun. (Camb.), 2242-2243, 2002.

16) L. Wu, R. G. Cooks. Chiral analysis using the kinetic method with optimized fixed ligands: Application to some antibiotics. Anal. Chem. 75: 678-684, 2003.

17) S. Kumari, S. Prabhakar, M. Vairamani, C. L. Devi, G. K. Chaitanya, $\mathrm{K}$. Bhanuprakash. Chiral discrimination of $\mathrm{D}$ - and $\mathrm{L}$-amino acids using iodinated tyrosines as chiral references: Effect of iodine substituent. J. Am. Soc. Mass Spectrom. 18: 1516-1524, 2007.

18) S. Kumari, S. Prabhakar, M. Vairamani. Halogen-substituted phenylalanines as enantioselective selectors for enantioselective discrimination of amino acids: Effect of halogen. Rapid Commun. Mass Spectrom. 22: 1393-1398, 2008.

19) X. L. Kong. Chiral differentiation of amino acids by the kinetic method with a FT ICR MS from a different dissociation pathway. Rapid Commun. Mass Spectrom. 26: 870-873, 2012.

20) R. Karthikraj, S. Prabhakar, M. Vairamani. Differentiation of enantiomeric drugs by iodo-substituted L-amino acid references under electrospray ionization mass spectrometric conditions. Rapid Commun. Mass Spectrom. 26: 1385-1391, 2012.

21) R. Tuytten, F. Lemière, E. L. Esmans, W. A. Herrebout, B. J. van der Veken, E. Dudley, R. P. Newton, E. Witters. In-source CID of guanosine: Gas phase ion-molecule reactions. J. Am. Soc. Mass Spectrom. 17: 1050-1062, 2006.

22) Y.-Q. Xia, M. Jema. High-field asymmetric waveform ion mobility spectrometry for determining the location of in-source collision-induced dissociation in electrospray ionization mass spectrometry. Anal. Chem. 81: 7839-7843, 2009.

23) L. Abranko, J. F. Gracia-Reyes, A. Molina-Diaz. In-source fragmentation and accurate mass analysis of multiclass flavonoid conjugates by electrospray ionization time-of-flight mass spectrometry. J. Mass Spectrom. 46: 478-488, 2011.

24) H. Zhai, X. M. Han, K. Breuker, F. W. McLafferty. Consecutive ion activation for top down mass spectrometry: Improved protein sequencing by nozzle-skimmer dissociation. Anal. Chem. 77: 5777-5784, 2005.

25) V. Gabelica, E. D. Pauw. Internal energy and fragmentation of ions produced in electrospray sources. Mass Spectrom. Rev. 24: 566-587, 2005. 